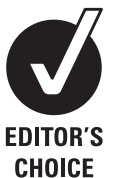

CHOICE
${ }^{1}$ Division of General Internal Medicine, Department of Medicine, University of California, San Francisco, Center for Vulnerable Populations, San Francisco General Hospital, San Francisco, California, USA ${ }^{2}$ Department of Epidemiology and Biostatistics and Division of General Internal Medicine, University of California, San Francisco Center for Vulnerable Populations, San Francisco General Hospital, San Francisco, California, USA

${ }^{3}$ Department of Medicine, University of California, San Francisco, San Francisco, California, USA

${ }^{4}$ Department of Public Health, San Francisco, California, USA ${ }^{5}$ Division of Endocrinology, Department of Medicine, San Francisco General Hospital, University of California, San Francisco, San Francisco, California, USA

${ }^{6}$ Department of Medicine, University of Toronto and Sunnybrook Health Sciences Centre, Toronto, Ontario, Canada

\section{Correspondence to}

Urmimala Sarkar, Division of General Internal Medicine, University of California, San Francisco, Box 1364, San Francisco, CA 94143-1364, USA;

usarkar@medicine.ucsf.edu

Accepted 13 April 2009

\title{
What happens between visits? Adverse and potential adverse events among a low-income, urban, ambulatory population with diabetes
}

\author{
U Sarkar, ${ }^{1}$ M A Handley, ${ }^{2}$ R Gupta, ${ }^{3}$ A Tang, ${ }^{4}$ E Murphy, ${ }^{5}$ H K Seligman, ${ }^{1}$ \\ K G Shojania, ${ }^{6}$ D Schillinger ${ }^{1}$
}

\begin{abstract}
Background Little is known about adverse events (AEs) that occur between physician visits for ambulatory chronic disease patients. An automated telephone selfmanagement support programme for a diverse population of diabetes patients was implemented to capture AEs, describe the self-management domains from which they emanate and explore contributing causes.
\end{abstract}

Methods AEs and potential AEs (PotAEs) were identified among 111 ethnically diverse diabetes patients. An AE is an injury that results from either medical management or patient self-management; a PotAE is an unsafe state likely to lead to an event if it persists without intervention. Medical record reviews were conducted to ascertain which self-management domain was involved with the event and to explore contributing causes.

Results Among the 111 patients, $86 \%$ had at least one event detected over the 9-month observation period. 111 AEs and 153 PotAEs were identified. For all events, medication management was the most common domain (166 events, 63\%). Only 20\% of events reflected a single contributing cause; in the remaining $80 \%$, a combination of system, clinician and patient factors contributed to their occurrence. Patient actions were implicated in 205 (77\%) events, systems issues in $183(69 \%)$ events and inadequate physician-patient communication in 155 (59\%) events. Aside from communication, primary care clinician actions contributed to the occurrence of the event in only 16 cases (6\%).

Conclusions Our findings reveal a complex safety ecology, with multiple contributing causes for AEs and PotAEs among ambulatory diabetes patients. Moreover, patients themselves seem to be key drivers of safety and of AEs, suggesting that patient-level self-management support and patient-centred communication are critical to $A E$ prevention.

Given the complexity of ambulatory management, ${ }^{1}$ many people with type 2 diabetes mellitus must independently complete complex tasks to manage their health. ${ }^{2}$ Although ambulatory care has increasingly been included in patient safety research, ${ }^{3-6}$ gaps remain in the current understanding of ambulatory safety, particularly for those with chronic diseases.

Prior work in ambulatory patient safety has focused largely on discrete, one-time events, including adverse drug events ${ }^{4-6}$ and medical errors, ${ }^{7-10}$ such as events after hospital discharge, identified in malpractice claims in ambulatory settings ${ }^{10} 11$ or resulting in emergency department visits. ${ }^{12}$ Some studies have used ambulatory incident reporting ${ }^{813-15}$; however, this captures a relatively small subset of adverse events (AEs). ${ }^{13-17}$ There has been a recent focus on errors and AEs occurring in the context of home healthcare, particularly after hospital discharge. ${ }^{18-21}$ Moreover, prior work in telephone case management has suggested that such interventions may detect medically urgent situations among patients at home. ${ }^{22}$ Thus, in this study, we used an interactive telephone technology to specifically examine safety in diabetes patients' most familiar environment-at home, between visits.

Ambulatory diabetes care provides an exemplary model to understand chronic disease safety. Diabetes is a communication-sensitive disease; communication barriers such as inadequate health literacy and limited English proficiency can contribute to suboptimal quality of care. ${ }^{23-25}$ Moreover, since patients must perform daily self-management behaviours, ${ }^{26-28}$ much of diabetes care occurs outside of the clinical setting. To address patients' selfmanagement needs beyond the clinical encounter, some health systems have developed mechanisms to communicate with diabetes patients at home, through health information technology strategies. $^{29-32}$ Surveillance of these communication encounters provides a unique opportunity to describe AEs and potential AEs (PotAEs) that arise between visits.

In the course of implementing an automated telephone self-management (ATSM) support programme for patients with diabetes, ${ }^{33}$ nurse care managers identified that patients were reporting self-management difficulties and barriers, and AEs and PotAEs. In a prior publication, ${ }^{34}$ we described the yield of the ATSM as a surveillance system. In this article, we describe the events uncovered, the self-management domains from which they emanate and their contributing causes.

\section{METHODS}

\section{Setting and patients}

This study was nested within the Improving Diabetes Efforts Across Language and Literacy (IDEALL) project, ${ }^{33}$ a 9-month, three-arm randomised trial of two diabetes self-management support interventions compared with usual care for adults with type 2 diabetes, described in past publications. ${ }^{33-35}$ We measured health literacy using the short-form Test of Functional Health Literacy Assessment (TOFHLA), ${ }^{36}$ for English and Spanish patients only. We examined patient safety among the 111 patients who participated in the ATSM intervention. The Committees on Human 
Research at the Community Health Network of San Francisco and the University of California, San Francisco, approved the study protocol.

\section{ATSM support}

ATSM is a health IT application that provides patient education and self-management support. ${ }^{31}$ 37-42 The IDEALL ATSM intervention included weekly interactive, automated telephone calls to patients, with review and follow-up by a nurse care manager. ${ }^{43}$ The ATSM application generated daily written output of patient responses. The nurse care manager reviewed these reports and followed up via telephone with those patients whose responses triggered a call-back based on preset criteria for each self-management query (eg, for the query, "How many days in the past 7 days did you exercise?", a response of "0" triggered a call-back). Then, they completed a standardised progress note for each telephone encounter. The primary goal of the ATSM system was to support patient self-management and behaviour change, not safety surveillance.

\section{Candidate event detection}

Candidate events could come to light in three ways. First, certain preset call-back criteria were considered safety thresholds. For instance, a patient-entered blood glucose value of less than $60 \mathrm{mg} / \mathrm{dl}$ would trigger a call-back from the nurse care manager and would be considered a candidate AE. Second, a patient could request a call-back from the nurse during any ATSM call. Third, patients could report an unrelated event during a live telephone nurse encounter. For example, during a call about exercise, a nurse could elicit that a patient did not have his diabetes medicines.

Because we could not confirm events if the nurse had been unable to reach the patients by telephone, we excluded those candidate events. In addition, we did not include events if the nurse care manager spoke with the patient but did not explicitly document confirmation of the candidate event.

\section{Ambulatory taxonomy and event ascertainment}

Our model, with "longitudinal" surveillance among a cohort of diabetes patients, required that we adapt existing taxono-

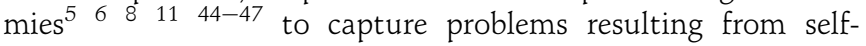
management of chronic diseases and to describe events as they developed over time. The taxonomy that we developed has been described in greater detail in a previously published report, ${ }^{34}$ and $\mathrm{AE}$ and PotAE definitions are provided in table 1.

Table 1 Definitions and selected examples of events

\begin{tabular}{l} 
Adverse event \\
Definition: An injury, with varying possible levels of harm, which may result from \\
medical management or patient self-management \\
Examples \\
Polyuria and polydipsia from severe hyperglycaemia. Patient ran out of insulin \\
because he was told to increase dose at prior visit but was not given a new \\
prescription. \\
Periodic hypoglycaemia; patient gets sweaty and shaky with midday exercise \\
Potential adverse event \\
Definition: An unsafe state, not currently an event, but likely to lead to an event if it \\
persists without intervention \\
Examples \\
Despite physician prescription, pharmacy does not dispense correct glucometre \\
strips because of formulary change. Patient unable to check glucose and continues \\
to administer insulin in the absence of any monitoring. \\
Patient with chronic kidney disease (asymptomatic) taking non-steroidal \\
anti-inflammatory drugs despite instruction to discontinue. \\
\hline
\end{tabular}

To operationalise these definitions, we convened a consensus group of clinicians and developed several clinical thresholds a priori. Next, two study physicians independently reviewed ATSM call records and ATSM progress notes to identify candidate events. They subsequently reviewed these candidate events jointly and included events that met the definitions and thresholds, and any disagreements were brought to the consensus panel for final determination as an $\mathrm{AE}$ or a PotAE

\section{Domains and contributing causes}

Two study physicians assigned each event to one of several possible self-management domains. The following domains were identified: medication use, diet, symptom recognition, exercise, self-monitoring of blood glucose, foot care and appointment adherence. Next, we explored possible contributing causes for the events we uncovered. Drawing on prior taxonomies, ${ }^{84}$ our taxonomy grouped contributing causes into four broad areas: systems issues, patient-clinician communication issues, patient contribution (apart from patient-clinician communication) and clinician contribution (apart from patient-clinician communication). Recognising that patient safety problems are usually multifactorial, ${ }^{5} 4748$ our taxonomy allows for coding of all applicable contributing causes for each event. If the two physician-reviewers could not determine whether a contributing cause was present from the medical records, it was coded as "unknown". Definitions and examples of contributing causes can be found in table 2 .

\section{Table 2 Definitions and examples of contributing causes}

\section{Systems issues}

Definition: The health system structure, organisation, processes or equipment contributed to the event, such as lack of availability of clinical information, poor transitions in care settings, lack of self-management support or system resources. Examples

Medication availability: physicians are unaware of formulary changes because they are not updated in the electronic prescribing system.

Diagnostic results: test results sent only to ordering clinicians, not to primary care providers

Impaired patient-clinician communication

Definition: Inadequate exchange of relevant information contributed to the event, such as language barrier, failure to convey/elicit symptoms or lack of patient understanding.

Examples

Health literacy: patient was unable to read prescription label; taking acetaminophen instead of metformin.

Physician unaware: patient has significant gastrointestinal distress leading to nonadherence with metformin, unknown to physician*

Patient contribution

Definition: A patient action or inaction, not related to clinician communication, contributed to event, such as harmful health beliefs, treatment non-adherence and financial barriers.

Examples

Health belief: patient refuses to initiate insulin despite worsening diabetes control because he believes it is responsible for his relative's amputation.

Insurance lapse: patient cannot pay for medications; his Medicaid lapsed when he failed to complete needed paperwork.

Clinician contribution

Definition: A clinician action or inaction, not related to clinician communication, contributed to event, such as errors in diagnosis and treatment, inadequate monitoring or failure to review relevant information.

Examples

Dosage error: physician prescribes twice the maximum daily dose of pioglitazone. Inadequate monitoring: physician does not order serum creatinine and potassium following initiation of an ACE inhibitor.

*The medical record did not allow coders to determine whether the clinician failed to elicit symptoms or the patient failed to report them. 
Table 3 Example events and coding scheme

Case 1. A 69-year-old man with diabetes has had worsening diabetes control. His primary care physician doubles the dose of his current metformin, adds glyburide and pioglitazone, and schedules follow-up in 4 months. When he begins the telephone self-management support intervention 2 months later, he requests a call-back from the study nurse. He reports that since his last visit, he has had frequent episodes of feeling sweaty and shaky, with blood sugar of 50s, two to three times per week. He had not informed anyone of these symptoms and did not know that they were related to his diabetes medicines.

Coding element

Event type: Adverse event

Self-management domain: medication use

Contributing cause: clinician

Contributing cause: communication

Contributing cause: patient

Harm

Case 2. A 57-year-old woman responses to the automated call triggered a call-back from the nurse care regarding diabetes diet. During the live call, she described some uncertainty about her medications. She was recently hospitalised for an exacerbation of congestive heart failure and renal insufficiency, and received new prescriptions upon discharge. When she returned home, she had a bottle of benazapril $20 \mathrm{mg}$ tablets from before her admission and a new bottle of benazapril $40 \mathrm{mg}$ tablets prescribed by the hospital physicians. She had been taking both, on the assumption that her hospital physicians were adding them to her prior regimen.

Coding element

Event type: potential adverse event

Self-management domain: medication use

Contributing cause: communication

Contributing cause: systems

Harm

\begin{abstract}
Rationale
Harm to patient (symptoms)

Directly related to medication escalation Patient did not convey symptoms to a clinician

Symptoms, $>1$ day

\section{Rationale}

No documented harm, but risk from unintended high dose of medication

Directly related to medication change in different care setting

Patient did not comprehend medication instructions

Lack of a standardised postdischarge medication reconciliation process None
\end{abstract}

Aggressive medication intensification without follow-up visit or other monitoring before 4 months

Patient unaware of the relationship between higher doses of diabetes medications and his symptoms

\section{Severity}

Although there are several existing severity scales for AEs, ${ }^{49} 50$ we chose to apply a widely used six-level classification, ranging from no harm up to and including death, developed by Bates

\section{Event characterisation and classification}

Following event ascertainment, the two physicians jointly reviewed all other patient-related documentation as previously described. ${ }^{34}$ They applied the patient safety taxonomy described above to characterise each event. If the medical record did not allow the coders to determine aspects of the taxonomy, the field was coded as "unable to determine". For illustration, two example events and their coding scheme are shown in table 3 .

\section{Data analysis}

We tabulated event characteristics, including the number of events in each self-management domain, and the distribution of contributing causes of events. Because we hypothesised that patients with limited health literacy and limited English proficiency might experience different events, we explored whether (1) the self-management domains and (2) the contributing causes of events differed by language preference and by health literacy (categorised as inadequate, TOFHLA score 0-16; marginal, 17-22; adequate, $23-36$. $)^{36}$

\section{RESULTS}

\section{Sample}

The 111 patients who participated in at least one ATSM call were ethnically and linguistically diverse, and most participants had long-standing, poorly controlled diabetes (table 4). In addition, $53 \%$ had limited health literacy, with TOFHLA scores of 22 (ie, "marginal") or lower.

We detected and confirmed 264 events, including 111 AEs and 153 PotAEs over the 9-month surveillance period. In addition to these confirmed events, 8 possible events were excluded because the ATSM nurse could not contact the patient (3\%) and 12 possible events were excluded because they were not confirmed during subsequent ATSM nurse call-backs (4\%). Ninety-six patients $(86 \%)$ experienced at least one event. et al. ${ }^{4-6} 10115152$

\section{Self-management domains}

The most common self-management domain implicated in AEs and PotAEs was medication use (table 5). Patients frequently experienced difficulties obtaining prescribed medications at pharmacies, leading to significant gaps in medication use that could jeopardise safety. In addition, patients' understanding of medication instructions and purposes frequently contributed to incorrect or suboptimal use. For AEs, dietary adherence and symptom recognition were also frequently involved. Dietary non-adherence led to symptoms of hypoglycaemia and hyperglycaemia. On occasion, patients failed to recognise that their symptoms (including urinary symptoms and new-onset fevers) required medical attention. For PotAEs, inability to monitor glucose was a common problem among patients adjusting insulin or self-titrating oral medications.

Table 4 Baseline patient characteristics, $n=111$

\begin{tabular}{|c|c|}
\hline Characteristic & \\
\hline Age, years, mean (SD) & $55.3(12.8)$ \\
\hline Female, n (\%) & $65(59)$ \\
\hline \multicolumn{2}{|l|}{ Time since diagnosis, years } \\
\hline \multicolumn{2}{|l|}{ Race/ethnicity, n (\%) } \\
\hline Non-Hispanic white & $10(9)$ \\
\hline African American & $16(14)$ \\
\hline Hispanic & $52(47)$ \\
\hline Asian & $30(27)$ \\
\hline Other & $3(3)$ \\
\hline \%HbA1c, mean (SD) & $9.3(1.8)$ \\
\hline \multicolumn{2}{|l|}{ Health literacy, ${ }^{*}$ n (\%) } \\
\hline Inadequate & $43(44)$ \\
\hline Marginal & $7(9)$ \\
\hline Adequate & $48(47)$ \\
\hline \multicolumn{2}{|l|}{ Language, n (\%) } \\
\hline English & $51(46)$ \\
\hline Spanish & 47 (42) \\
\hline Cantonese & $13(12)$ \\
\hline Insulin use, n (\%) & $40(36)$ \\
\hline Oral medications, n (\%) & $100(90)$ \\
\hline Poor or fair health status, $\mathrm{n}(\%)$ & $82(74)$ \\
\hline No of completed calls, mean (SD) & $16(9)$ \\
\hline No of nurse call-backs, mean (SD) & $10(7)$ \\
\hline
\end{tabular}


Table 5 Self-management domains for adverse and potential adverse events

\begin{tabular}{lcc}
\hline & $\begin{array}{l}\text { AEs } \\
\text { n (\%) }\end{array}$ & $\begin{array}{l}\text { PotAEs } \\
\text { n (\%) }\end{array}$ \\
\hline Medication use & $66(59)$ & $100(65)$ \\
Diet adherence & $23(21)$ & $5(3)$ \\
Symptom recognition & $16(14)$ & 0 \\
Glucose monitoring & $1(1)$ & $46(30)$ \\
Diabetes foot care & $1(1)$ & 0 \\
Appointment adherence & 0 & $1(1)$ \\
Unable to determine & $4(4)$ & $1(1)$ \\
Total & 111 & 153 \\
\hline
\end{tabular}

AEs, adverse events; PotAEs, potential adverse events.

\section{Contributing causes}

We identified systems issues, patient-physician communication problems, and clinician and patient actions (apart from communication) that played a part in events. Most events had multiple contributing causes (figure 1). For nine events (3\%), medical record review did not reveal a contributing cause. Fiftytwo $(20 \%)$ events had only one detected contributing cause, 106 (40\%) had two causes, 93 (35\%) had three causes and 4 (2\%) had a contribution from all four possible causes. Patient actions were implicated in 205 (77\%) of events. Systems issues contributed to 183 events (69\%), impaired patient-clinician communication contributed to 155 (59\%) events and primary care clinician actions contributed to $16(6 \%)$ events.

In our exploratory analysis, we found that the distribution of self-management domains from which events emanated differed by health literacy level, such that those with inadequate and marginal health literacy had a higher proportion of events related to symptom recognition and a lower proportion of events related to diet $(p=0.01)$. There were no differences in distribution of self-management domains by language $(p=0.67)$. The distribution of contributing causes did not differ by language $(p=0.77)$ or health literacy $(p=0.15)$.

\section{DISCUSSION}

We provide the first detailed, longitudinal analysis of AEs and PotAEs between visits among vulnerable type 2 diabetes patients. The overwhelming majority experienced at least one $\mathrm{AE}$ or PotAE, and most events were related to medication use. We found that events commonly had multiple contributing causes. The frequency with which patient actions contribute to

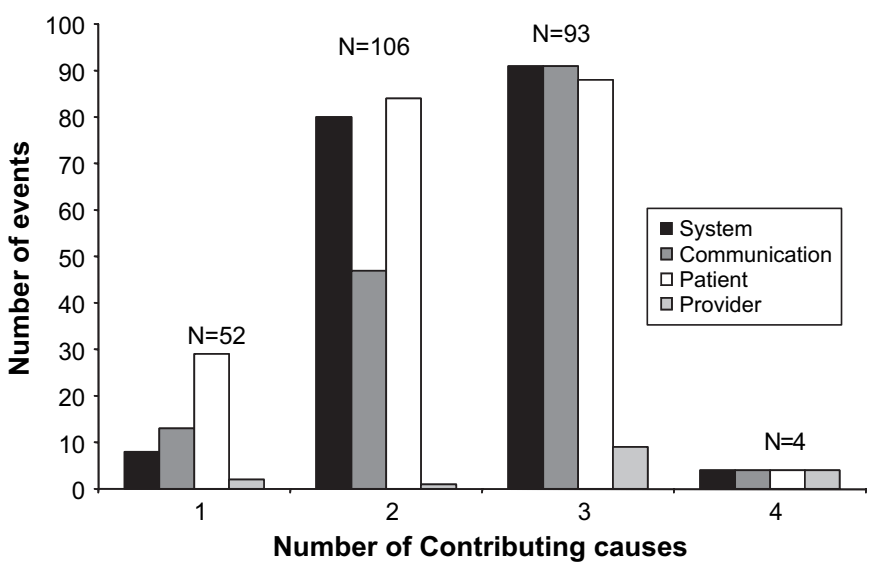

Figure 1 Frequency and distribution of contributing causes for events $(\mathrm{N}=264)$.
AEs and PotAEs suggests that improving safety will require extensive patient education, support and surveillance.

Consistent with prior literature, ${ }^{4-64853-56}$ our results suggest that efforts to improve ambulatory patient safety in diabetes should focus on medication safety and monitoring. In contrast with the inpatient setting, in which patients receive medications ordered and administered to them, ambulatory patients must actively participate in medication management by obtaining their medications at the pharmacy, understanding and correctly carrying out medication instructions, consistently adhering to their regimen and carrying out monitoring as necessary. Problems at any of these stages may jeopardise safety.

Similar to other studies among ambulatory transplant recipients, ${ }^{48}$ and of closed malpractice claims, ${ }^{10}$ we found patient actions and inactions to be a significant contributing cause for events. Thus, to be effective, ambulatory safety strategies must adopt a patient-centred approach, ${ }^{57}$ in which systems and clinicians facilitate the patients' ability to comprehend and carry out optimal self-management. Efforts to improve safety should take the perspective of the patient who is navigating the ambulatory environment and build in safeguards for common obstacles, from obtaining clear medication instructions to completing transitions among clinicians or between the ambulatory and acute-care settings.

In addition, our analysis of contributing causes revealed that system inadequacies contributed to the majority of events. Compared with hospitals, the ambulatory environment presents unique challenges to implementing system-level interventions, including fragmentation of care and less regulatory scrutiny, ${ }^{59-61}$ and inadequate penetration of health information technology. ${ }^{62}{ }^{63}$ Interventions that address system-level barriers and patient-clinician communication are needed to improve safety for ambulatory diabetes patients.

Despite its strengths, this study has several limitations. First, because our sample was a socioeconomically disadvantaged, racially/ethnically and linguistically diverse group with poor health status, our findings may not be generalisable to all ambulatory diabetes patients, and may partly explain the ubiquity of events and distribution of self-management domains and contributing causes. Notably, those with limited health literacy had more events related to inadequate symptom recognition compared with other participants; further studies are needed to characterise the role of communication barriers in ambulatory safety. Second, we harnessed a health IT-facilitated self-management support application to explore patient safety. The system was not designed to systematically identify threats to patient safety, nurses were not specially trained or instructed to identify or elicit threats to patient safety, and patients varied in their degree of engagement with the system. ${ }^{64}$ As such, we may have underestimated the number of events, as is true for other methods of event detection and reporting. ${ }^{13-15} 1765$ Third, event ascertainment by review requires clinical judgement ${ }^{66} 67$ and can vary from clinician to clinician. Similar to prior studies, we used a two-physician review model. ${ }^{11}{ }^{6568-70}$ Future work in ambulatory patient safety research will need to arrive at common definitions and validate thresholds. Fourth, because event ascertainment was retrospective, we needed to use chart review to investigate contributing causes; we did not use a technique such as root cause analysis ${ }^{71-75}$ or failure mode effects analysis ${ }^{76}$ to definitively establish event causation. We are currently planning prospective AE surveillance using ATSM support in which we will be able to perform real-time, thorough event investigation.

Ambulatory diabetes patients frequently face safety problems in the course of self-managing their disease. Especially in the area 
of medication use, patients require support beyond usual care to avoid AEs. In applying our results to safety promotion efforts in the ambulatory setting, health systems should focus on medication safety, improve systems of care and suboptimal communication, and, most importantly, address the primary role of the patient in performing safe self-management of chronic diseases.

Funding US is supported by Agency for Healthcare Research and Quality K08 HS017594. Support for this research was also provided by The Commonwealth Fund and The California Health Care Foundation. The views presented here are those of the authors and should not be attributed to The Commonwealth Fund, California Health Care Foundation, or their directors, officers or staff. DS and MAH were also supported by grants from Agency for Healthcare Research and Quality R21 HS014864 and Agency for Healthcare Research and Quality R18 HS01726101. Electronic data were made available through the support of $\mathrm{NIH}$ grant UL1 RR024131. KGS received salary support from the Government of Canada Research Chairs Program. Other Funders: NIH.

\section{Competing interests None.}

Ethics approval This study was conducted with the approval of the University of California, San Francisco, San Francisco General Hospital.

Provenance and peer review Not commissioned; externally peer reviewed.

\section{REFERENCES}

1. Hofer TP, Zemencuk JK, Hayward RA. When there is too much to do: how practicing physicians prioritize among recommended interventions. J Gen Intern Med 2004; 19:646-53.

2. Tierney WM. Adverse outpatient drug events-a problem and an opportunity. N Engl J Med 2003;348:1587-9.

3. Elder NC, Vonder Meulen M, Cassedy A. The identification of medical errors by family physicians during outpatient visits. Ann Fam Med 2004;2:125-9.

4. Gandhi TK, Burstin HR, Cook EF, et al. Drug complications in outpatients. J Gen Intern Med 2000:15:149-54.

5. Gandhi TK, Weingart SN, Borus J, et al. Adverse drug events in ambulatory care. N Engl J Med 2003;348:1556-64.

6. Gurwitz JH, Field TS, Harrold LR, et al. Incidence and preventability of adverse drug events among older persons in the ambulatory setting. JAMA 2003;289:1107-16.

7. Elder NC, Dovey SM. Classification of medical errors and preventable adverse events in primary care: a synthesis of the literature. J Fam Pract 2002:51:927-32.

8. Fernald DH, Pace WD, Harris DM, et al. Event reporting to a primary care patient safety reporting system: a report from the ASIPS collaborative. Ann Fam Med 2004: 2:327-32.

9. Rosser W, Dovey $S$, Bordman R, et al. Medical errors in primary care: results of an international study of family practice. Can Fam Physician 2005;51:386-7.

10. Gandhi TK, Kachalia A, Thomas EJ, et al. Missed and delayed diagnoses in the ambulatory setting: a study of closed malpractice claims. Ann Intern Med 2006:145:488-96.

11. Forster AJ, Murff HJ, Peterson JF, et al. The incidence and severity of adverse events affecting patients after discharge from the hospital. Ann Intern Med 2003:138:161-7

12. Budnitz DS, Pollock DA, Weidenbach KN, et al. National surveillance of emergency department visits for outpatient adverse drug events. JAMA 2006;296:1858-66

13. Cullen DJ, Bates DW, Small SD, et al. The incident reporting system does not detect adverse drug events: a problem for quality improvement. Jt Comm J Qual Improv 1995:21:541-8.

14. O'Neil AC, Petersen LA, Cook EF, et al. Physician reporting compared with medicalrecord review to identify adverse medical events. Ann Intern Med 1993;119:370-6.

15. Schmidek JM, Weeks WB. Relationship between tort claims and patient incident reports in the Veterans Health Administration. Qual Saf Health Care 2005;14:117-22.

16. Sari $\mathbf{A B}$, Sheldon TA, Cracknell A, et al. Sensitivity of routine system for reporting patient safety incidents in an NHS hospital: retrospective patient case note review. BMJ 2007;334:79.

17. Phillips R, Dovey S, Graham D, et al. Learning from different lenses: reports of medical errors in primary care by clinicians, staff, and patients. J Patient Saf 2006; $2: 140-6$

18. McGraw C. Drennan V Humphrey C. Understanding risk and safety in home health care: the limits of generic frameworks. Qual Prim Care 2008;16:239-48.

19. Wachter R. Understanding patient safety. New York: McGraw Hill, 2008

20. Hauck M, Bauer A, Voss F, et al. "Home monitoring" for early detection of implantable cardioverter-defibrillator failure: a single-center prospective observational study. Clin Res Cardiol 2008;98:19-24.

21. Tsilimingras D, Bates DW. Addressing postdischarge adverse events: a neglected area. Jt Comm J Qual Patient Saf 2008;34:85-97.

22. Izquierdo R, Meyer S, Starren J, et al. Detection and remediation of medically urgent situations using telemedicine case management for older patients with diabetes mellitus. Ther Clin Risk Manag 2007;3:485-9.

23. Schillinger $\mathbf{D}$, Wang $\mathrm{F}$, Rodriguez $\mathrm{M}$, et al. The importance of establishing regimen concordance in preventing medication errors in anticoagulant care. $J$ Health Commun 2006; 11:555-67.
24. Kripalani S, LeFevre F, Phillips C0, et al. Deficits in communication and information transfer between hospital-based and primary care physicians: implications for patient safety and continuity of care. JAMA 2007:297:831-41.

25. Shojania KG, Ranji SR, McDonald KM, et al. Effects of quality improvement strategies for type 2 diabetes on glycemic control: a meta-regression analysis. JAMA 2006:296:427-40.

26. Fisher EB, Brownson CA, O'Toole ML, et al. Ecological approaches to selfmanagement: the case of diabetes. Am J Public Health 2005;95:1523-35.

27. Institute of Medicine. Crossing the quality chasm: a new health system for the $21 \mathrm{st}$ century. Washington, DC: National Academy Press, Institute of Medicine Committee on Quality of Health Care in America, 2001.

28. Mensing C, Boucher J, Cypress M, et al. National standards for diabetes self-management education. Task Force to Review and Revise the National Standards for Diabetes Self-Management Education Programs. Diabetes Care 2000:23:682-9.

29. Gerber BS, Brodsky IG, Lawless KA, et al. Implementation and evaluation of a low-literacy diabetes education computer multimedia application. Diabetes Care 2005;28:1574-80.

30. Piette J, Weinberger M, McPhee S. The effect of automated calls with telephone nurse follow-up on patient-centered outcomes of diabetes care. Med Care 2000;38:218-30

31. Piette JD, Weinberger M, Kraemer FB, et al. Impact of automated calls with nurse follow-up on diabetes treatment outcomes in a Department of Veterans Affairs Health Care System: a randomized controlled trial. Diabetes Care 2001:24:202-8.

32. Shea S, Weinstock RS, Starren J, et al. A randomized trial comparing telemedicine case management with usual care in older, ethnically diverse, medically underserved patients with diabetes mellitus. J Am Med Inform Assoc 2006:13:40-51.

33. Handley M, Hammer H, Schillinger D. Navigating the terrain between research and practice: a Collaborative Research Network (CRN) case study in diabetes research. J Am Board Fam Med 2006:19:85-92.

34. Sarkar U, Handley M, Gupta R, et al. Use of an interactive, telephone-based self-management support program to identify adverse events among ambulatory diabetes patients. J Gen Intern Med 2008:23:459-65.

35. Schillinger D, Hammer H, Wang F, et al. Seeing in 3-D: examining the reach of diabetes self-management support strategies in a public health care system. Health Educ Behav 2007;35:664-82.

36. Parker RM, Baker DW, Williams MV, et al. The test of functional health literacy in adults: a new instrument for measuring patients' literacy skills. J Gen Intern Med 1995; 10:537-41.

37. Aubert RE, Herman WH, Waters $\mathrm{J}$, et al. Nurse case management to improve glycemic control in diabetic patients in a health maintenance organization. A randomized, controlled trial. Ann Intern Med 1998;129:605-12.

38. Chumbler NR, Neugaard B, Ryan P, et al. An observational study of veterans with diabetes receiving weekly or daily home telehealth monitoring. J Telemed Telecare 2005;11:150-6.

39. Piette JD, McPhee SJ, Weinberger M, et al. Use of automated telephone disease management calls in an ethnically diverse sample of low-income patients with diabetes. Diabetes Care 1999;22:1302-9.

40. Weinberger M, Kirkman MS, Samsa GP, et al. A nurse-coordinated intervention for primary care patients with non-insulin-dependent diabetes mellitus: impact on glycemic control and health-related quality of life. J Gen Intern Med 1995;10:59-66.

41. Piette JD, Weinberger M, McPhee SJ. The effect of automated calls with telephone nurse follow-up on patient-centered outcomes of diabetes care: a randomized, controlled trial. Med Care 2000;38:218-30.

42. Piette JD, Weinberger M, McPhee SJ, et al. Do automated calls with nurse follow-up improve self-care and glycemic control among vulnerable patients with diabetes? Am $J$ Med 2000;108:20-7.

43. McLean I, Schneiderman M, Palacios J, et al. Extra care for diabetes: automated telephone disease management protocol. New York: Commonwealth Fund, 2004.

44. Chang A, Schyve PM, Croteau RJ, et al. The JCAHO patient safety event taxonomy: a standardized terminology and classification schema for near misses and adverse events. Int J Qual Health Care 2005;17:95-105.

45. The Linnaeus-PC Collaboration. International taxonomy of medical errors in primary care version 2. Washington, DC: The Robert Graham Center, 2002.

46. Victoroff M, Pace W. ASIPS-Victoroff dimensions of medical outcome taxonomy. 2005.

47. Dovey SM, Meyers DS, Phillips RL Jr, et al. A preliminary taxonomy of medical errors in family practice. Qual Saf Health Care 2002:11:233-8.

48. Friedman AL, Geoghegan SR, Sowers NM, et al. Medication errors in the outpatient setting: classification and root cause analysis. Arch Surg 2007;142:278-83; [discussion 284].

49. Food and Drug Administration. Title 21-Food and drugs, Chapter 1 FDA, HHS, subchapter D-Drugs for human use, 2008. http://www.accessdata.fda.gov/scripts/ $\mathrm{cdrh} / \mathrm{cfdocs} / \mathrm{cfcfr} / \mathrm{cfrsearch} . \mathrm{cfm}$ ? cfrpart $=312$

50. Institute for Safe Medication Practices. FMEA scoring guidelines, 2005. http:// ismp.org/Tools/FMEAofPCA.pdf

51. Bates DW, Cullen DJ, Laird N, et al. Incidence of adverse drug events and potentia adverse drug events. Implications for prevention. ADE Prevention Study Group. JAMA 1995:274:29-34.

52. Gandhi TK, Sittig DF, Franklin M, et al. Communication breakdown in the outpatient referral process. J Gen Intern Med 2000;15:626-31. 
53. Gandhi TK, Weingart SN, Seger AC, et al. Outpatient prescribing errors and the impact of computerized prescribing. J Gen Intern Med 2005;20:837-41.

54. Hanlon JT, Schmader KE, Koronkowski MJ, et al. Adverse drug events in high risk older outpatients. J Am Geriatr Soc 1997:45:945-8.

55. Hutchinson TA, Flegel KM, Kramer MS, et al. Frequency, severity and risk factors for adverse drug reactions in adult out-patients: a prospective study. J Chronic Dis 1986;39:533-42.

56. Plews-Ogan ML, Nadkarni MM, Forren $\mathrm{S}$, et al. Patient safety in the ambulatory setting. A clinician-based approach. J Gen Intern Med 2004;19:719-25.

57. Hibbard JH, Peters E, Slovic P, et al. Can patients be part of the solution? Views on their role in preventing medical errors. Med Care Res Rev 2005;62:601-16.

58. Buetow S, Elwyn G. Patient safety and patient error. Lancet 2007;369:158-61.

59. Wachter RM. Expected and unanticipated consequences of the quality and information technology revolutions. JAMA 2006;295:2780-3.

60. Wachter RM. Is ambulatory patient safety just like hospital safety, only without the "stat"? Ann Intern Med 2006;145:547-9.

61. Wagner EH. Chronic disease management: what will it take to improve care for chronic illness? Eff Clin Pract 1998;1:2-4.

62. Linder JA, Ma J, Bates DW, et al. Electronic health record use and the quality of ambulatory care in the United States. Arch Intern Med 2007:167:1400-5.

63. Baron RJ, Fabens EL, Schiffman M, et al. Electronic health records: just around the corner? Or over the cliff? Ann Intern Med 2005;143:222-6.

64. Schillinger D, Hammer $H$, Wang $F$, et al. Seeing in 3-D: examining the reach of diabetes self-management support strategies in a public healthcare system. Health Educ Behav 2008;35:664-82.

65. Thomas EJ, Lipsitz SR, Studdert DM, et al. The reliability of medical record review for estimating adverse event rates. Ann Intern Med 2002;136:812-16.

66. Standards of medical care in diabetes-2007. Diabetes Care 2007;30(Suppl 1): S4-S41.
67. Hayward RA, Hofer TP. Estimating hospital deaths due to medical errors: preventability is in the eye of the reviewer. JAMA 2001;286:415-20.

68. Brennan TA, Leape LL, Laird NM, et al. Incidence of adverse events and negligence in hospitalized patients. Results of the Harvard Medical Practice Study I. N Engl J Med 1991;324:370-6

69. Leape LL, Brennan TA, Laird N, et al. The nature of adverse events in hospitalized patients. Results of the Harvard Medical Practice Study II. N Engl J Med 1991;324:377-84.

70. Thomas EJ, Studdert DM, Burstin HR, et al. Incidence and types of adverse events and negligent care in Utah and Colorado. Med Care 2000;38:261-71.

71. Bittle MJ, Charache P, Wassilchalk DM. Registration-associated patient misidentification in an academic medical center: causes and corrections. Jt Comm J Oual Patient Saf 2007;33:25-33.

72. Iedema RA, Jorm C, Braithwaite J, et al. A root cause analysis of clinical error: confronting the disjunction between formal rules and situated clinical activity. Soc Sci Med 2006;63:1201-12.

73. Rex JH, Turnbull JE, Allen SJ, et al. Systematic root cause analysis of adverse drug events in a tertiary referral hospital. Jt Comm J Qual Improv 2000; 26:563-75.

74. Shojania KG, Duncan BW, McDonald KM, et al. Making health care safer: a critica analysis of patient safety practices. Evid Rep Technol Assess (Summ) 2001(43):i-x 1-668.

75. Veterans' Affairs National Center for Patient Safety. Root Cause Analysis. http://www4.va.gov/NCPS/rca.html

76. Veterans' Affairs National Center for Patient Safety. The Basics of Health Care Failure Mode and Effects Analysis. http://www4.va.gov/ncps/SafetyTopics/HFMEA/ HFMEAIntro.pdf

77. Institute for Healthcare Improvement. Failure Modes and Effects Analysis (FMEA) Too (IHI Tool). 